CONCLUSION

The above paragraphs give a general view of the present status of refining light oil in the United States. Besides, at present, some light oil is produced so far from refineries as to make it impractical to transport it to a point where it can be utilized. Such light oil is mostly used up as a thinner in cheap tar paints.

Up to the present, the manufacture of products in this field has been mainly confined to materials already existent in the crude oil, and capable of being isolated by physical and simple chemical means. The further, more intricately chemical manufacture of the various derivatives of benzene, toluene, naphthalene, etc., which serve as raw materials for dye manufacture, has as yet been carried on only in a comparatively small way in the United States.

The chemical possibilities along these lines are yet to be developed in this country, and here indeed is a wide field for technical endeavor which will place the coal tar industry of the United States in a stage of development equal to that already attained abroad.

NEW YoRK CiTY

\section{THE PAST, PRESENT, AND FUTURE OF THE NAVAL STORES INDUSTRY ${ }^{1}$}

By Charles H. Herty

The limited use of the oleoresinous exudate of pine trees dates back many centuries, but the real beginning of an industry on a large scale is closely associated with the discovery of the vast pine forests which extend along the southeastern and southern coasts of the United States from North Carolina to Texas.

These forests lie chiefly in the coastal plain and in the slightly hilly country between the piedmont plateau and the coastal plain, a strip varying in width from one hundred to two hundred miles and characterized by a sandy soil, covered for the most part with "wire grass," this furnishing a beautiful carpet of green in spring and summer, but making a serious fire risk in winter. The longleaf pine readily sheds its lower limbs, especially in close stands, so that the forests are remarkably open and free from that undergrowth, which, in the northwest, leads to such destructive forest fires.

The early settlers in eastern North Carolina began the exploitation of their forests of longleaf pine for the purpose of providing tar and pitch for use in the construction of wooden ships, and gradually extended their operations to the collection of crude turpentine which was shipped to northern cities or England for distillation. The forests covered the entire territory and, as clearings for farms were needed, destructive methods of operation were welcomed and encouraged.

At the same time limited operations were being conducted upon the maritime pine in southwestern France between Bordeaux and Bayonne. To receive the crude turpentine the French made use of a hole dug in the sand at the base of the tree. The oleoresin flowing from the wound on the trunk above was collected in these holes. Necessarily by this method much of the material was wasted and rendered impure.

\section{AMERICAN METHOD OF COLLECTION}

In North Carolina the method of collection was improved, or thought to be improved, by cutting a large opening, the "box," in the base of the tree. Into this box the crude turpentine flowed and was collected at regular intervals. The conservative character of the men engaged in this industry led to the continuance of this wasteful and destructive method of "boxing" until the very recent past.

Briefly, the method of operating so long in use in the United

1 Paper presented at the Eighth International Congress of Applied Chemistry, New Xork, September, 1912.
States is as follows: In the winter the laborers are engaged in cutting "boxes." Each box is then "cornered," a wide chip being removed from each half of the box to provide a surface suitable for directing the flow of crude turpentine to the box. Meanwhile, other laborers are employed in clearing all combustible material from around each tree, "raking." Ground fires are then started to consume the dead wire grass, chips, etc. With the opening of Spring, "chipping" begins. This consists in scarifying each week the trunk of the tree above the "cornered" surface by means of a "hack," a U-shaped stcel tool set in a wooden handle. Attached to this handle is a heavy iron weight to give momentum to the free arm swing used in chipping. After four or five weeks the "boxes" average a good filling and the crude turpentine, "dip," is then transferred to buckets by flat iron paddles, and from the buckets it is collected in barrels conveniently placed in the woods. In the Fall, at the end of the chipping season, the hardened oleoresin, which has gradually collected during the chipping season on the scarified surface of the tree, is removed by scraping, giving thus the name "scrape" to this product, which is sold as "Gum Thus," or distilled. In the following Winter the trees are again raked and the grass fired, and in the Spring chipping is resumed at the point on the trunk of each tree where it ceased the previous year. This cycle is usually continued from three to four years, although in early days it was of ten continued ten or twelve years, the scarified surface extending high on the trunks. Necessarily the yield from such high chipping was largely decreased, owing to the increased distance of flow to the receptacle.

In the early days of the North Carolina industry, no effort was made to distill the product, but gradually it became clear that it would be better to separate the crude turpentine into spirits of turpentine and rosin by distillation in the woods. For this purpose iron stills were used at first, but results were unsatisfactory until the introduction of copper stills, which were less liable to crack and could be heated with greater uniformity and better control.

The industry now began to grow rapidly and before many years it was found that the supply of available timber in North Carolina was rapidly decreasing. This led many of the operators to transfer their operations to the virgin forests of the adjoining state, South Carolina, where the same destructive methods were applied by the same men or their descendants. In this way, and for these reasons, the center of the industry has gradually moved southward and then westward as evidenced by the relative prominence of the ports for exports of the products: first Wilmington, N. C., then Charleston, S. C., then Savannah, Ga., and now the latter, together with Jacksonville, Fla., and the gulf ports, Tampa, Fla., Pensacola, Fla., Mobile, Ala., Gulfport, Miss., New Orleans, La., and others.

\section{FRENCH IMPROVEMENTS}

The steady growth of the American industry received a serrious check during the Civil War. The consequent scarcity of the products was accompanied by an abnormal increase in their value. This enhanced valuation led Hugues, a Frenchman, to propose a less wasteful method for the French forests than the hole dug in the sand. He proposed as a substitute a clay pot holding about one pint. This pot was supported on its bottom by a large nail driven into the tree and on one side of its upper rim by a strip of sheet zinc, approximately 2 inches $\times 4$ inches, slightly curved and driven into a corresponding upwardly inclined cut in the wood. This spout served to direct the oleoresin into the pot. At first his proposition was scoffed at and the peasants amused themselves by breaking the little pots. It is a pitiful commentary that Hugues died in poverty, but his ideas lived and gradually became adopted in France.

\section{AMERICAN IMPROVEMENTS}

As the knowledge of the new method in France spread to this 
country, numerous efforts were made to apply similar forms of apparatus to the American system of chipping, but for many years such efforts failed. No less than fifteen patents were issued in the United States on this subject, but no one of them proved a commercial success.

Eleven years ago the writer began a series of field experiments on a small scale in the turpentine forests of South Georgia. One feature of these experiments was the use of a modification of the Hugues system, consisting of two separate metallic gutters, inserted in upwardly inclined cuts in the tree, along which the oleoresin flows. The upper and shorter gutter is separated at its lower end about one inch from the lower gutter and empties into it. The lower gutter extends from two to three inches beyond the center of the angular scarified surface formed in chipping and serves as a spout to convey the oleoresin to a cup suspended from a nail just below the end of the gutter. These cups are made of either well burned clay or galvanized iron, and have a capacity of one quart.

Attracted by the promising character of these preliminary experiments, the U. S. Bureau of Forestry began a series of field tests of the apparatus on a large scale, the work being under the immediate supervision of the writer. Before the end of the first season of testing it was evident that the apparatus was a practical success, and the results attained, both as to quantity and quality of oleoresin, justified the hope of immediate commercial introduction of the system. But the habits of long years made difficult the adoption of such an innovation. This ultra-conservatism was slowly overcome and the adoption of the new system spread rapidly. Only a few years more will be required to witness the complete replacement of the "box" by the "cup" system in American forests. A detailed account of these experiments is given in Bulletin 40 and Circular 34 of the U. S. Bureau of Forestry.

With the main points at issue settled, namely, improved yields both in quantity and quality of the products and prescrvation of the trees, other forms of apparatus were devised to meet the objections of some of the operators to certain points in the cup and gutter system. Many of these have never proved practical, but some have been introduced on a considerable commercial scale.

The successful outcome of the experiments on the relative yields from the "box" and the "cup" system led the United States Forest Service to further experiments in more conservative treatment of the trees in chipping. Comparative studies were made of the yield from deep and shallow chipping and the latter found to give the greater yield during a period of four years of operation. Other experiments showed that a less rapid rate of ascent of the trunk also gave larger yields, and experiments combining these several modifications of present practices showed a largely increased yield. A final set of experiments pointed clearly the rational way to a perpetuation of the naval stores industry in America. The details of this investigation are given in Bulletin 90 of the United States Forest Service.

\section{DISTILLATION}

In the matter of distillation, only slight advances have been made in America. The uniform process consists in the use of a large copper kettle and condensing worm. The charge for a distillation averages nine to ten barrels of crude turpentine. The kettle is heated by free flame and during the distillation a small stream of hot water from the top of the condenser tub is admitted through an opening in the upper part of the kettle, thus facilitating the removal of the volatile oil. The condensed spirits of turpentine and water separate in the receiver, owing to difference in specific gravity, and the lighter spirits of turpentine is transferred to oak barrels, well coated with glue on the inside. No effort is made to redistill this product, and it always comes upon the market contaminated by a small amount of resin carried over mechanically during distillation. After most of the volatile oil has passed off, the still cap is removed, excess water in the kettle boiled off, and the molten rosin drawn off through a tap in the bottom of the kettle onto a coarse wire filter, then through a second filter of fine mesh wire overlaid with cotton batting. The molten rosin is then dipped into wooden barrels luted with clay and solidifies on cooling. In this condition it is shipped to market.

The usual method of controlling the distillation is by the sound heard at the mouth of the condenser worm. Within the past three years a number of American operators have substituted for this method that of thermometer control with very excellent results.

In France, much more progress has been made in the art of distillation. Among the French distilleries there are three distinct types: first-a system closely resembling the American; second-distillation solely by steam in steam jacketed vessels; and third-a mixed system in which there is direct contact of fire with the kettle during the first stage of the distillation, then replacement of this by mixed injection of steam and hot water. By this means, a constant temperature is maintained, enabling the complete removal of all spirits of turpentine without danger of scorching the rosin.

It can readily be understood that in France, under proper methods of forestry, with conservative tapping of the trees and provision for systematic reforestration, a distillery can look forward to a permanent supply of raw material. Hence there is justification for the more costly plants and more efficient methods of distillation; but in America, where under past methods the industry shifts so rapidly, so great an outlay of capital for this purpose would not be justified. There is no doubt that with an excellent "stiller" very good results can be obtained under the American system, but the personal element of the stiller enters into the question, and this could be easily avoided without any great outlay of capital by adopting the French system of mixed injection.

Quite recently M. Castets has erected near Dax, France, a distillery which combines the features of continuous distillation in a partial vacuum and condensation by pressure of the waste spirits of turpentine vapors from the ordinary condenser in a second condenser attached to the first, thus increasing notably the yield of volatile oil and improving the quality of the rosin.

\section{THE INDUSTRY IN OTHER COUNTRIES}

There is no need of any especial consideration of the Spanish industry, which has developed considerably during the past decade. The operations are essentially the same as the French, and the same species of pine, Pinus Maritima, is exploited.

In Austria the industry is more limited and is even more destructive than by the old American system, a "box" being cut in the base of the tree, Pinus Laricio, and the trunk of the tree scarified for at least fifty per cent. of its circumference, the oleoresin being directed towards the center of the scarified surface by thin wooden strips inserted in downward cuts in the tree.

In Russia the chief tree exploited is Pinus Sylvestris. Climatic conditions do not admit of the usual process of collecting the crude turpentine at regular intervals. Instead, the trees are scarified in Spring over a space about three feet high and almost encircling the tree. During the year a mass of hardened rosin collects on this surface. In the Winter it is scraped from the tree and distilled for its volatile oil and resin. This process is repeated for five years. The tree is then felled and the resinous portion of the tree subjected to destructive distillation. In other districts no effort is made to collect the rosin from the trees annually, but this is allowed to remain until the end of the fifth year of scarification. The tree is then felled and that part containing the rosin distilled first at a low temperature to obtain the volatile oil, then at a more elevated temperature to obtain tar and charcoal by destructive distillation of the wood. 
The spirits of turpentine from Germany, Sweden, and Finland seems to be a product solely of the destructive distillation of resinous wood.

The production of naval stores in India and other tropical countries is at present on too small a commercial scale to call for any detailed discussion here.

\section{WOOD SPIRITS OF TURPENTINE}

Among the various departments of the naval stores industry in America none has had a more varied and interesting career than that of the production of "wood spirits of turpentine" by destructive distillation of resinous wood. Years ago considerable capital was invested in plants for utilizing the byproducts formed during the destructive distillation of "fat lightwood." None of the plants were commercially successful and for a while nothing was heard of the industry. But with the increase in price of spirits of turpentine resulting from the formation of the Turpentine Operators Association in 1902, a fresh impetus was given to the "wood spirits of turpentine" industry. At first somewhat crude methods of destructive distillation were advocated, and as the promoters of this industry appealed largely to local interest in having stumps for distillation removed from fields suitable for cultivation, a double impetus was received. Much enthusiasm was aroused, and a number of plants constructed. But the industry received a serious blow in the refusal of the varnish makers to use the impure "wood spirits of turpentine" manufactured, by the failure to find a market for many of the heavier oils and the coke, and by the destruction by fire of many of the improperly constructed plants.

The price of spirits of turpentine continued to rise and led to the development of the steam extraction process for manufacture of wood spirits of turpentine. After thorough grinding, the wood is treated in iron retorts with steam, and the volatile oil distilled, no effort being made to obtain any other product. By one redistillation of the product a very high-grade spirits of turpentine is obtained, equal, if not superior, to that from the living tree. Unfortunately, the yield is not sufficiently large to make the process remunerative.

Quite a different process is employed by those plants which utilize a bath of molten rosin for removal of the spirits of turpentine from the wood, with subsequent distillation of the volatile oil from this bath. Such plants seem to have met with a fair measure of success.

More recently, extraction processes have been developed which employ low-boiling petroleum products as the extractive. Such plants recover both the spirits of turpentine and the rosin from the ground wood, and have a great advantage in the present very high value of rosin. These plants are also utilizing the refuse from the straining of rosin at the distilleries in the woods, a product formerly burned on the waste piles, but now bringing nineteen dollars per ton. This method is adding a considerable amount to the annual output of rosin.

The most recent development is a plant for destructive distillation of wood in retorts heated by jackets filled with highboiling petroleum fractions. By this means the fire risk is practically completely eliminated and the results indicate that by means of the complete and ready temperature control of the oil jacket larger yields of better products can be obtained. ANNCAL PRODCCTION OF NAVAL STORES

No subject connected with the naval stores industry admits of so little accuracy of statement as does that of statistics on the total annual production. The most careful estimates are at best only approximations. This is unfortunate, for in the past it has frequently led to speculative manipulations of the market and the temporary establishment of values which had no legitimate basis depending on supply and demand.

The following table of annual production is given, therefore, as an approximation only, but it is believed to be a reasonably accurate approximation:

\begin{tabular}{|c|c|c|c|}
\hline $\begin{array}{l}\text { Spirits } \\
\text { barrels }\end{array}$ & $\begin{array}{l}\text { of turpentine } \\
\text { ( } 52 \text { gallons) }\end{array}$ & * & $\begin{array}{c}\text { Rosin } \\
\text { barrels (500 lbs.) }\end{array}$ \\
\hline$\ldots \ldots \ldots \ldots$ & 600,000 & & $2,100,000$ \\
\hline France... & 100,000 & & 350,000 \\
\hline Spain............... & 25,000 & & 87,500 \\
\hline Austria ............ & 3,000 & & 10,500 \\
\hline Other countries.......... & $50,000(?)$ & & \\
\hline \multicolumn{3}{|c|}{ Total estimated production 778,000} & $2,548,000$ \\
\hline
\end{tabular}

PRODLCTION OF CRUDE TURPENTINE PER TREN

Here again definite figures are difficult to give, for there is no reliable information concerning the number of trees in operation. Furthermore, there is often very wide variation in the producing power of adjacent trees of the same species, size, and crown. But from the data in the publications of the United States Forest Service, an average American pine, worked under the cup system, will produce, during four years of operation, an annual average of ten pounds of crude turpentine and two and a half pounds of "scrape," the proportionate yield being considerably greater during the first and second than during the third and fourth years of operation.

The average daily flow of crude turpentine during one week from a freshly chipped surface on such pines is shown in the following table, the results having been obtained during the summer of Igor on trees near Statesboro, Georgia:

\begin{tabular}{|c|c|c|c|c|c|}
\hline \multicolumn{4}{|c|}{ Yield per tree (grams) } & \multirow{2}{*}{$\begin{array}{c}\text { Average yield } \\
\text { (grams) }\end{array}$} & \multirow{2}{*}{$\begin{array}{l}\text { Per cent. } \\
\text { average yielo }\end{array}$} \\
\hline Day & 1 & 2 & 3 & & \\
\hline 1 & 113.0 & 46.5 & 89.0 & 82.8 & 62.9 \\
\hline 2 & 22.5 & 7.5 & 16.0 & 15.3 & 11.6 \\
\hline 3 & 13.5 & 6.5 & 16.0 & 12.0 & 9.1 \\
\hline 4 & 9.0 & 5.0 & 17.0 & 7.0 & 5.3 \\
\hline $5 \& 6$ & 9.0 & 5.0 & 23,0 & 12.3 & 9.3 \\
\hline 7 & 1.0 & 2.0 & 4.0 & 2.3 & 1.8 \\
\hline Total & 168.0 & 72.5 & 165.0 & 131.7 & 100.0 \\
\hline
\end{tabular}

TSCHIRCH'S VIEWS ON RESIN FLOW

As to the seat of resin production and cause of resin flow, most valuable and important views have been advanced by Prof. A. Tschirch in his book, "Die Harze und die Harzbehälter," and edition. Tschirch has shown that the seat of resin production is a mucilaginous layer lining the inner walls of the resin ducts. These ducts he divides into two classes: First-primary ducts, whose resin is to be considered a true physiological product. Such ducts occur irregularly and in varying number in any pine. They play only an insignificant tôle as producers of commercial crude turpentine. Second-secondary resin ducts which form in large numbers in the outer layers of the new wood after a tree is wounded, both above and below the wound. Their oleoresinous exudate is, therefore, a pathological product. It is from such pathological ducts that the great bulk of crude turpentine is obtained.

The application of these views to practical problems in the turpentine forests has already yielded important and fruitful results.

\section{FUTLRE OF THE INDLSTRY}

During the past few years the statement has frequently been made that from present indications the naval stores industry must cease to exist, at least as a large industry, within the next twenty years. While it is true that there are danger signals which must be heeded, such pessimistic views do not seem to be well grounded.

Certainly in France and consequently in Spain, where the same system is in operation, the industry has been placed upon a self-perpetuating basis.

In America we have been prodigal with our wealth of virgin forest. But it must be remembered that until the last decade these forests have had a very low commercial valuation. The average 
price for well timbered lands in our southern states not many years ago was approximately one dollar per acre, land, timber, and all. Indeed, the popular term applied to all holders of large tracts of such lands was "land poor," as expense of taxation, protection, etc., exceeded any hope of probable profit. This condition was largely due to lack of transportation facilities, insecurity of title, low price of naval stores and lumber, lack of knowledge of the farming value of much of the land on which these forests stood, and the belief that the forests were inexhaustible.

Now conditions have entirely changed. Railroads penetrate every portion of the territory, titles have been cleared, prices of naval stores have brought wealth to the operators, the lumbermen from Michigan, Wisconsin, and other northern states have turned from the rapidly disappearing white pine forests of the north to those of the southern yellow pine; where forests once stood farms have been developed which surpass in fertility any other portion of the southern states, and a clear knowledge has been gained that the forests are by no means inexhaustible. Furthermore, the spirit of conservation of natural resources has made itself felt in this field as well as in those of minerals, waterpower, etc.

The consequence of these changes has been a very rapid enhancement in the value of such holdings. And with increased valuation comes naturally the desire to protect and use conservatively. Unquestionably, the stand of virgin forest will still further diminish, for the demand for farm lands is active, the call for lumber imperative, and the danger of tropical storms along the Gulf Coast ever present. With such diminution in supply will come still further enhancement in values and still more conservative methods of operation.

So much for the present stand of virgin forest. If the situation was limited to this alone, the outlook might be considered gloomy. But it must be remembered that there are vast tracts of cut-over lands in portions of the southern states whose clay sub-soil lies so deep that the lands are not suited to agriculture. On such lands the longleaf pine, with its long tap root, prospers. Magnificent forests once covered every acre of such lands and fortunately tree planting is not required to reproduce such forests. Nature alone will again cover this territory with a wealth of forest, provided nature is given an opportunity; for the most superficial observer who travels through this territory will testify that where conditions have been favorable natural reproduction has brought again splendid, though small, young forests.

Against this willingness of nature to restore this rich heritage to us, stand three agencies.

First, and of least. importance: The consumption by hogs of the delicately flavored and nutritious feed of the longleaf pine. This is a real factor in certain somewhat restricted districts. The constantly spreading sentiment for "stock laws" will check this evil.

Second, and of the very greatest importance: The destructive action of the ground fires, which annually sweep over the entire turpentine belt. Such fires destroy the myriads of young seedlings which can readily be seen springing up in the wire grass which surrounds them on every side. The seedling devotes the greater part of its early energies to sending down its long tap root through the deep sands rather than to strengthening its stalk above ground; hence, in most cases, it is not able to withstand the constantly recurring ground fires. The doctrinaire may rail against the evils of such firing of the woods, but from one who has lived among the turpentine camps there comes no word of reproach against the turpentine operator who "burns the woods." His all is invested on the outer surface of his trees. A serious outbreak of fire during midseason means financial ruin. The carelessness and sometimes viciousness of laborers is too serious a risk to run with a mass of dead wire grass covering every foot of his territory. Naturally he protects himself by burning this grass when he is prepared for it, after "raking season."

Where then is the hope for reforestration? In the realization of the value of the waste cut-over lands where turpentine operations cannot be carried on for lack of timber. Such lands have now but little value, but the lesson of France shows that even there a reasonable income begins from artificial reproduction within a period of twenty years and then rapidly increases. With our warm southern climate the prospect for rich returns from such investments should be even greater than in France.

Third, The greed of man. If we are to have a self-perpetuating industry, even stock laws and the reforestration of waste lands will not avail if a practice on the part of turpentine operators during the past two years continues. The abnormally high price of spirits of turpentine two years ago led to a wild scramble for timber for increased operations. At the same time the efficiency of the "cup" system was just gaining wide recognition. Realizing that a tree too small to have a "box" cut in it could be worked with a cup hung upon it, the operators throughout the whole region proceeded to cup every small tree to which access could be gained. In many cases new farms were opened on old abandoned territory where natural reproduction had furnished thrifty young forests. The result was overproduction of crude turpentine. The temporary benefit to the consumers in the drop in values following this overproduction was dearly bought, for the price was the destruction of young forests which, in time, should have produced their full share of the world's need of spirits of turpentine and rosin. Common sense must and will govern in this matter. It is only necessary for the operators to realize that the yield from such saplings does not meet the cost of production; then the practice will cease.

Surely the above considerations justify an optimistic view of the future of the naval stores industry. But experiment, demonstration, statistics, and knowledge of progress made in other lands, must lead the way for the man in the woods.

University OF NoRth CAROLINA Chapel HiLl

\section{THE TECHNICAL PROBLEMS OF COAL PREPARATION ${ }^{1}$}

By W. S. AYres

The problems involved in the preparation of coal begin in the mine itself and before the coal is even cut, and end with the loading of the prepared product into transportation cars ready for market. For the solution of these problems the engineer must bring to his aid geology, petrology, mineralogy, chemistry, hydrostatics, pneumatics and mechanics. These sciences have, after much study and a long-continued experimentation with every variety of coal, divulged the limits within which their respective groups of natural laws can be used for the accomplishment of the end sought. Any practice outside of these definite limits is sure to lead to disaster.

Having these guiding principles at hand, the continuity, uniformity, and structural nature of the beds of coal are determined, from which the system of mining and cutting is formulated; the physical peculiarities of both the coal and the refuse are carefully studied and the methods of handling and preparation are definitely selected; the degree of purity possible in the preparation, the possible percentage of recovery, the economy of the process adopted, and the market value of the prepared product are also determined.

In the mine it is of great importance to first determine the recoverable tonnage in the coal beds, and from this data to determine the daily capacity of the proposed preparation plant.

The method of mining the several seams should be governed chiefly by the manner in which the refuse is associated with the

1 Paper presented at the Eighth International Congress of Applied Chemistry, New York, September, 1912. 